\title{
PERENCANAAN KEBUTUHAN MATERIAL DENGAN METODE MATERIAL REQUIREMENT PLANNING
}

\author{
JAKA PURNAMA DAN SUHARTINI \\ Jurusan Teknik Industri, Fakultas Teknologi Industri, \\ Institut Teknologi Adhi Tama Surabaya \\ Jl. Arif Rahman Hakim 100 Surabaya 60117 \\ Surel: jakapurnama99@yahoo.com; ttitin63@yahoo.com
}

\begin{abstract}
ABSTRAK
Kegiatan produksi yang dilakukan oleh beberapa perusahaan masih menggunakan persediaan material yang banyak agar kegiatan produksi dapat berjalan lancar, akan tetapi kondisi ini dianggap tidak optimal karena banyak sumber daya yang ditanam, sehingga investasi hanya digunakan untuk keperluan kebutuhan material. Pemesanan material yang tidak didukung dengan data-data permintaan produk secara tepat, akan membuat persediaan bahan baku tidak dapat dipastikan sehingga material terkadang banyak dan kadang kala habis. Dalam menggunakan tenaga kerja dan fasilitas produksi yang tidak sesuai dengan kebutuhan permintaan, maka kegiatan produksi tidak berjalan secara efektif dan efisien. Sumber daya yang dimiliki oleh perusahaan harus diketahui secara detail, agar perusahaan dapat menggunakan kemampuan sumber daya yang ada secara optimal. Perusahaan dalam mencapai permintaan produk harus mengetahui kapasitas produksi yang dimiliki, sehingga kemampuan target produksi perusahaan dapat dicapai secara optimal, dengan melakukan pengukuran waktu standar pada operasi kerja dan menentukan performance rating untuk masing-masing operator. Dalam menentukan permintaan produk untuk periode berikutnya menggunakan metode peramalan jenis regresi linier dengan jumlah permintaan produk sebesar $1278 \mathrm{~kg}$. Perencanaan kebutuhan material (MRP) pesanan dapat dilakukan pada hari ke-7 tiap bulan sesuai dengan jumlah masing-masing jenis bahan baku.
\end{abstract}

Kata kunci: waktu standar, operasi kerja, permintaan, material

\begin{abstract}
Production activities which are conducted by some companies still use a lot of material inventory that production activities can run smoothly, but this condition is not considered optimal because many sources in the plant, so the investment is only in use for material. Ordering a material is not supported by data appropriately in product demand, it will make inventory of raw materials can not be sure so that the material is sometimes a lot and sometimes run out. The use of labor and production facilities are not accordance with demand, finally the production activities are not effective and efficient. Resources owned by the company must to be known in detail, so that the company can use capabilities of existing resources optimally. Company to achieve product demand should know the productive capacity, so that the ability of the company's production targets can be achieved optimally, by measuring standard time at work operations and determine performance rating for each operator. In determining the demand for the product the next period using the method of linear regression forecasting the number of types of product demand of 1278 kg. Material requirements planning (MRP) orders can be made on day 7 of each month in accordance with the number of each type of raw material.
\end{abstract}

Key words: standard time, work operations, demand, material 


\section{PENDAHULUAN}

Perencanaan produksi merupakan bagian penting yang harus dilakukan di industri manufaktur. Perencanaan produksi bertujuan untuk menentukan jumlah produk yang harus dihasilkan dengan waktu yang sesuai dengan jadwal produksi, sehingga proses produksi dapat berjalan dengan lancar dan ekonomis. Perencanaan produksi yang baik akan dapat meningkatkan keuntungan perusahaan karena mampu meminimalkan biaya produksi dan dapat memenuhi kebutuhan dari permintaan produk. Sasaran perusahaan melakukan perencanaan produksi untuk menetapkan tingkat output secara menyeluruh dalam jangka waktu tertentu untuk menghadapi permintaan pasar yang bersifat fluktuatif atau tidak pasti. Aktivitas peramalan merupakan suatu fungsi bisnis yang berusaha memperkirakan penjualan dan penggunaan produk sehingga produk-produk itu dapat dibuat dalam kuantitas yang tepat. Dengan demikian peramalan merupakan suatu dugaan terhadap permintaan yang akan datang berdasarkan beberapa variabel peramalan, sering berdasarkan data deret waktu historis. Aktivitas peramalan biasa dilakukan oleh departemen pemasaran dan hasil-hasil dari peramalan ini sering disebut sebagai ramalan penjualan (Gaspersz, 2005). Pemilihan item-item independent demand yang akan diramalkan tergantung pada situasi dan kondisi aktual dari masing-masing industri manufaktur. Namun yang terpenting bagi manajemen industri adalah memperhatikan bahwa item-item independent demand adalam item-item yang bebas atau tidak terkait langsung dengan struktur bill of material (BOM) untuk produk akhir yang akan dibuat oleh industri manufaktur.

PT XYZ merupakan salah satu perusahaan manufaktur yang bergerak di bidang penyedia produk-produk tinta. Kegiatan produksi yang dilakukan masih ada operasi kerja yang mengalami keterlambatan proses dalam membuat produk tinta tersebut. Perusahaan berusaha mengoptimalkan seluruh sumber daya yang ada untuk mencapai target perusahaan dengan baik.
Produktivitas yang dimiliki perusahaan masih termasuk rendah, karena perusahaan masih belum mempunyai data yang akurat berhubungan dengan waktu baku di masing-masing operasi. Perusahaan belum mempunyai model peramalan permintaan yang baik, sehingga persediaan kebutuhan bahan baku untuk periode berikutnya belum bisa diketahui dengan pasti.

Berdasarkan kondisi tersebut maka perlu adanya perencanaan produksi yang baik agar dapat memenuhi permintaan pasar dengan tepat dan target produksi dengan biaya produksi yang minimal. Tujuan dari penelitian ini adalah menentukan perencanaan produksi dan jumlah persediaan kebutuhan bahan baku yang harus disiapkan.

\section{METODE}

Pengukuran waktu kerja adalah pekerjaan mengamati pekerja dan mencatat waktu kerjanya baik setiap elemen ataupun siklus kerja. Suatu pekerjaan akan dikatakan dapat diselesaikan secara efisien apabila waktu penyelesaiannya berlangsung secara singkat. Waktu baku yang dihasilkan dalam aktifitas pengukuran kerja ini dapat dipergunakan sebagai alat untuk membuat rencana penjadwalan kerja yang menyatakan berapa lama suatu kegiatan harus berlangsung dan berapa output yang akan dihasilkan. Waktu baku ini sudah meliputi kelonggaran waktu yang diberikan dengan memperhatikan situasi dan kondisi pekerjaan yang harus diselesaikan.

Menurut Wignjosoebroto (2008), teknik pengukuran waktu kerja ini dapat dikelompokkan menjadi dua, yaitu pengukuran waktu kerja secara langsung dan pengukuran waktu kerja secara tidak langsung. Dalam penelitian ini menggunakan metode pengukuran waktu kerja secara langsung. Metode pengukuran waktu kerja secara langsung dibagi menjadi dua, yaitu : dengan jam henti (Stop Watch Time Study) dan sampling kerja (Work Sampling). Dari kedua metode pengukuran kerja secara langsung di atas maka dalam penelitian ini metode yang digunakan adalah metode pengukuran kerja dengan jam henti (Stop Watch Time Study). 
Metode ini diaplikasikan untuk pekerjaanpekerjaan yang singkat dan berulang-ulang. Pengukuran ini digunakan untuk menghitung waktu kerja operator. Hasil dari pengukuran merupakan waktu baku yang dijadikan standar penyelesaian pekerjaan bagi pekerja yang akan melaksanakan pekerjaan yang sama. Aktifitas pengukuran jam henti umumnya diaplikasikan pada industri manufakturing yang meliputi : karakteristik kerja yang berulang-ulang, terspesifikasi dengan jelas, dan menghasilkan output yang relatif sama.

Langkah-langkah pengukuran kerja dengan jam henti (Wignjosoebroto, 2008):

a. Tahap persiapan

Pilih dan definisikan pekerjaan yang akan diukur dan akan ditetapkan waktu standarnya, informasikan maksud dan tujuan pengukuran kerja kepada supervisor atau pekerja, pilih operator, dan catat semua data yang berkaitan dengan sistem operasi kerja yang akan diukur waktunya.

b. Tahap breakdown elemen

Bagi siklus kegiatan yang berlangsung kedalam elemen-elemen kegiatan sesuai dengan satuan yang ada

c. Tahap pengamatan dan pengukuran

Peneliti melakukan pengamatan dan pengukuran waktu sejumlah $\mathrm{N}$ pengamatan untuk setiap siklus atau elemen kegiatan (X1, $\mathrm{X} 2, \mathrm{X} 3, \ldots \mathrm{Xn})$. Tentukan performance rating dari kegiatan yang ditunjukkan operator.

d. Cek keseragaman data

Peta kontrol adalah suatu alat yang tepat guna menganalisis keseragaman data yang diperoleh dari hasil pengamatan atau pengukuran kerja. Batas Kontrol Atas (BKA) atau Upper Control Limit (UCL) serta Batas Kontrol Bawah (BKB) atau Lower Control Limit (LCL) untuk mencari skala hasil pengamatan data grup bisa diformulasikan sebagai berikut (Wignjosoebroto, 2008) :

$\mathrm{BKA}=\bar{X}+\mathrm{k} \cdot \mathrm{SD}$

$\mathrm{BKB}=\bar{X}-\mathrm{k} . \mathrm{SD}$ e. Cek kecukupan data

Perhitungan jumlah data yang dibutuhkan untuk penelitian agar dicapai data yang cukup untuk penelitian.

$$
N=\left[\frac{k / s \sqrt{N\left(\sum x^{2}\right)-\left(\sum x\right)^{2}}}{\left(\sum x\right)}\right]^{2}
$$

Syarat data cukup apabila terpenuhi: $\mathrm{N}^{\prime} \leq \mathrm{N}$.

f. Perhitungan waktu normal

Waktu normal untuk suatu elemen operasi kerja adalah semata-mata menunjukkan bahwa seorang operator yang berkualifikasi baik akan bekerja menyelesaikan pekerjaan pada tempo kerja yang normal. Kenyataan operator akan sering menghentikan kerja dan membutuhkan waktu-waktu khusus untuk keperluan seperti personal needs, istirahat melepas lelah, dan alasan lain yang diluar kontrolnya. Rumus waktu normal menurut Wignjosoebroto (2008) :

Waktu Normal (Wn)

$=$ Waktu Pengamatan $\times \frac{\text { Rating Faktor } \%}{100 \%}$

Waktu Normal (Wn)

$=$ Waktu pengamatan $\mathrm{x}$ Performance Rating

Performance rating merupakan suatu aktivitas dari seorang operator yang menjalankan pekerjaannya secara normal dengan kecepatan atau tempo yang dimiliki oleh setiap operator. Nilai performance rating dengan sistem Westinghouse menurut Sutalaksana dkk. (2006) seperti pada Tabel 1 .

g. Perhitungan waktu standar

Waktu standar (baku) adalah waktu kerja normal untuk menyelesaikan suatu pekerjaan yang dilakukan operator ditambah dengan allowance time. Waktu baku dapat diperoleh dengan mengaplikasikan rumus sebagai berikut (Wignjosoebroto, 2008): 
Tabel 1. Performance Rating dengan Sistem Westinghouse

\begin{tabular}{lllllllllllll}
\hline \multicolumn{4}{l}{ Skill } & \multicolumn{4}{c}{ Effort } & \multicolumn{3}{c}{ Condition } & \multicolumn{3}{c}{ Consistency } \\
\hline & & & & & & & & & + & \\
+0.15 & A1 & Superskill & +0.13 & A1 & Superskill & +0.06 & A & Ideal & 0.04 & A & Ideal \\
& & & & & & & & & + & & \\
+0.13 & A2 & & +0.12 & A2 & & +0.04 & B & Excellent & 0.03 & B & Excellent \\
& & & & & & & & & + & & \\
+0.11 & B1 & Excellent & +0.10 & B1 & Excellent & +0.02 & C & Good & 0.01 & C & Good \\
+0.08 & B2 & & & +0.08 & B2 & & 0.00 & D & Average & 0.00 & D & Average \\
+0.06 & C1 & Good & +0.05 & C1 & Good & -0.03 & E & Fair & -0.02 & E & Fair \\
+0.03 & C2 & & & +0.02 & C2 & & -0.07 & F & Poor & -0.04 & F & Poor \\
0.00 & D & Average & 0.00 & D & Average & & & & & & \\
-0.05 & E1 & Fair & -0.04 & E1 1 & Fair & & & & & & \\
-0.10 & E2 & & -0.08 & E2 & & & & & & & \\
-0.16 & F1 & Poor & -0.12 & F1 1 & Poor & & & & & & \\
-0.22 & F2 & & -0.17 & F2 & & & & & & & \\
\hline
\end{tabular}

Waktu Standar (Ws)

$=$ Waktu Normal $x \frac{100 \%}{100 \%-\% \text { allowance }}$

Waktu longgar (allowance time) yang dibutuhkan dan menginterupsi proses produksi ini bisa diklasifikasikan menjadi 3 yaitu personal allowance, fatigue allowance, kelonggaran waktu karena keterlambatanketerlambatan (delay allowance).

h. Output Standar

Menurut Wignjosoebroto (2008), jumlah produk yang dihasilkan dari seorang operator dalam tiap periode waktu dapat diketahui, sehingga operator dapat diperkirakan dalam menghasilkan output produksi secara layak.

Output Standar

$$
=\frac{1}{\text { Waktu Standart }} \text { (unit/jam) }
$$

\section{Peramalan Perı nintaan}

Peramalan merupakan suatu kegiatan dengan menggunakan data maupun kejadian masa lalu sebagai dasar untuk meramalkan kegiatan yang akan terjadi pada masa yang akan datang. Fungsi peramalan untuk menentukan alokasi dan penggunaan bahan baku serta halhal lain yang berkaitan dengan perencanaan masa yang akan datang, dimana kepastiannya tidak tahu pasti kondisinya.

Nasution (1999) menyatakan pada umumnya peramalan dapat dibedakan dari beberapa segi, tergantung dari cara melihatnya. Dilihat dari segi penyusunnya, maka peramalan dapat dibedakan atas dua macam, yaitu :

1. Peramalan subjektif, yaitu peramalan yang didasarkan atas perasaan atau intuisi dari orang yang menyusunnya. Dalam hal ini pandangan atau "judgment" dari orang yang menyusunnya sangat menentukan baik tidaknya hasil peramalan tersebut.

2. Peramalan objektif, yaitu peramalan yang didasarkan atas data yang relevan pada masa lalu, dengan menggunakan teknik-teknik dan metode dalam penganalisisan data tersebut.

Ukuran akurasi hasil peramalan yang merupakan ukuran kesalahan peramalan merupakan ukuran tentang tingkat perbedaan antara hasil peramalan dengan permintaan yang sebenarnya terjadi. Ada 4 ukuran yang bisa digunakan untuk mengukur akurasi hasil peramalan yaitu MAD, MSE, MAPE, dan MFE. Rumus perhitungan yang digunakan menurut 
Nasution (1999) yaitu :

1. Rata-Rata Deviasi Mutlak (Mean Absolute Deviation)

$$
\mathrm{MAD}=\Sigma\left|\frac{\mathrm{At}-\mathrm{Ft}}{\mathrm{n}}\right|
$$

2. Rata-Rata Kuadrat Kesalahan (Mean Square Error)

$$
\operatorname{MSE}=\sum \frac{(\mathrm{At}-\mathrm{Ft})^{2}}{\mathrm{n}}
$$

3. Persentase Rata-rata Kesalahan Absolut (Mean Absolute Percentage Error)

$$
\mathrm{MAPE}=\left(\frac{100 \%}{n}\right) \Sigma\left|A t-\frac{\mathrm{Ft}}{\mathrm{At}}\right|
$$

4. Kesalahan Rata-Rata (Mean Forecast Error)

$$
\mathrm{MFE}=\sum \frac{(\mathrm{At}-\mathrm{Ft})}{\mathrm{n}}
$$

Dimana :

At : Permintaan aktual pada periode $t$

Ft : Peramalan permintaan pada periode $t$

$\mathrm{n}$ : Jumlah periode peramalan yang terlibat

\section{Perencanaan Kebutuhan Material (MRP)}

MRP (Material Requirement Planning) adalah sistem informasi yang merancang pesanan dan penjadwalan permintaan persediaan yang dependent (bahan baku, komponen, dan subassembly) yang dibutuhkan untuk mendukung jadwal induk produksi (Nasution, 1999). Menurut Handoko (2003), MRP adalah sistem persediaan yang pertama kali memperkenalkan bahwa persediaan bahan baku, komponen, dan barang jadi memerlukan penanganan yang berbeda. MRP dapat mengatasi masalah yang kompleks timbul dalam persediaan yang memproduksi banyak produk, masalah tersebut antara lain: kebingungan dan pelayanan yang tidak memuaskan para konsumen. MRP memang lebih kompleks pengelolaannya tapi dapat menghasilkan banyak keuntungan, seperti mengurangi biaya persediaan dan biaya produksi.
Tujuan utama sistem MRP adalah untuk mengontrol tingkat persediaan dan melaksanakan operasi prioritas untuk item-item yang dipesan, agar diperoleh material yang tepat, dan sumber daya yang tepat, untuk penempatan yang tepat, dan pada waktu yang tepat. Disamping itu sistem MRP mengidentifikasikan item apa yang harus dipesan, berapa kuantitas item yang harus dipesan, dan bilamana waktu memesan item itu. Ada tiga input yang dibutuhkan oleh sistem MRP (Gaspersz , 2005) yaitu jadwal induk produksi, catatan keadaan persediaan, dan struktur produk.

\section{Kapasitas Produksi}

Kapasitas produksi berdasarkan jumlah mesin dan jumlah tenaga kerja, digunakan untuk mengetahui perlu dilakukan waktu lembur atau sub kontrak, bila permintaan melebihi kapasitas yang ada. Perhitungan kebutuhan kapasitas mesin dan operator pada proses produksi dalam satu periode (Smith, 1989):

a. Kapasitas mesin/periode $=$ jumlah mesin $x$ (jumlah hari/periode) $\mathrm{x}$ (jumlah shift/hari) $\mathrm{x}$ (jumlah jam/shift)

b. Kapasitas operator/periode $=$ jumlah operator $\mathrm{x}$ (jumlah hari/periode) $\mathrm{x}$ (jumlah shift/hari) $\mathrm{x}$ (jumlah jam / shift)

Beberapa langkah diperlukan untuk analisis perencanaan kapasitas produksi yaitu :

1. Memperoleh informasi tentang pesanan produksi yang dikeluarkan (planned orders release) dari MRP.

2. Memperoleh informasi tentang standard run time per unit dan standard set up time per unit.

3. Menghitung kapasitas yang dibutuhkan dari masing-msing pusat kerja.

4. Membuat laporan perencanaan kapasitas produksi.

\section{Tahap-Tahap Penelitian}

Pada penelitian ini, tahapan disusun secara sistematis sehingga memudahkan bagi peneliti dalam melakukan penelitian supaya tujuan tercapai dengan baik. 
1. Tahap Identifikasi

a. Identifikasi Masalah, merupakan tahap awal yang memegang peranan penting dalam melakukan penelitian. Tujuannya untuk mencari faktor penyebab timbulnya suatu masalah.

b. Perumusan Tujuan Penelitian, merumuskan dan menetapkan masalah yang diteliti, maka selanjutnya adalah menentukan tujuan penelitian yang ingin dicapai dalam penelitian ini. Penetapan tujuan ini dilakukan untuk memberikan arah bagi jalannya penelitian.

c. Studi Pustaka dan Studi Lapangan, Studi pustaka dilakukan untuk memperoleh teori-teori yang mendukung dan berhubungan dengan permasalahan serta metode-metode yang akan dipakai untuk menyelesaikan permasalahan tersebut. Studi lapangan dilakukan untuk mengetahui kondisi sesungguhnya permasalahan yang ada di perusahaan, terutama di bagian proses produksi.

d. Penentuan Metode Penyelesaian, perusahaan masih menggunakan perencanaan produksi yang dibuat secara sederhana dan berdasarkan pengalaman produksi yang pernah ada, sehingga perusahaan belum mengetahui rencana produksi yang diterapkan sudah optimal atau belum. Selanjutnya dilakukan perencanaan produksi dan menentukan kebutuhan bahan baku yang akan digunakan untuk menyusun produk sesuai dengan permintaan yang akan datang dengan menggunakan metode Material Requirement Planning.

2. Tahap Pengumpulan dan Pengolahan Data Tahap ini pada dasarnya tidak hanya sekedar kegiatan pengumpulan data, tetapi juga merupakan suatu kegiatan pengklasifikasian dapat diuraikan sebagai berikut :

a. Identifikasi Variabel Penelitian, meliputi jenis produk, jumlah work center, dan variabel-variabel lain yang berhubungan dengan penelitian.

b. Pengumpulan Data, tahap ini merupakan tahap pengumpulan data-data yang diperlukan selanjutnya data tersebut akan diolah hasilnya sesuai dengan landasan teori yang digunakan. c. Pengolahan Data, dengan melakukan perhitungan data antara lain menguji keseragaman data, kecukupan data, menghitung waktu normal, waktu standar, dan output kerja operator. Kemudian dilakukan peramalan permintaan produk dengan mengunakan beberapa metode dan mengukur tingkat keakuratan berdasarkan nilai kesalahan peramalan yang paling kecil. Perencanaan produksi dan menentukan kebutuhan bahan baku yang akan digunakan untuk membuat produk berdasarkan permintaan yang akan datang dengan mengunakan metode Material Requirement Planning.

3. Tahap Analisis dan Kesimpulan

Tahap ini pada dasarnya berisi hasil-hasil yang diperoleh dari langkah sebelumnya yang kemudian dapat disimpulkan pada tahapan ini. Begitu pula saran-saran yang sangat berhubungan dengan hasil dan kesimpulan.

\section{HASIL DAN PEMBAHASAN}

Data permintaan masa lalu yang diambil selama 4 tahun dengan jumlah permintaan bersifat fluktuatif dapat dilihat pada Gambar 1 dan jumlah data pesananan berbeda-beda tiap periode menggunakan ukuran volume $(\mathrm{Kg})$ seperti ditunjukkan pada Tabel 2.

Data pengukuran waktu kerja untuk proses produksi ini diperoleh melalui pengamatan langsung. Pengamatan waktu kerja sebanyak 36 kali dengan menggunakan tingkat kepercayaan $=95 \%(\mathrm{k}=2)$ dengan tingkat ketelitian $(\mathrm{s})=5 \%$. Hasil perhitungan waktu standar dapat dilihat pada Tabel 3.

Dari data permintaan yang telah diketahui, maka dapat dilakukan peramalan untuk mengetahui jumlah permintaan tinta standar jenis PMW Blue untuk 6 bulan kedepan. Dari keempat metode peramalan tersebut akan dipilih metode yang mempunyai hasil akurasi terbaik. Dalam melakukan peramalan ini, penulis menggunakan bantuan Software QM.

Tabel 4 menunjukkan bahwa nilai hasil peramalan dari metode Linier Regression lebih akurat, karena perbandingan nilai MAD dan 
Tabel 2. Data Permintaan Tinta PMW Blue

\begin{tabular}{|c|c|c|c|c|c|}
\hline No. & Periode & $\begin{array}{c}\text { Permintaan } \\
(\mathbf{k g})\end{array}$ & No. & Periode & $\begin{array}{c}\text { Permintaan } \\
(\mathrm{kg})\end{array}$ \\
\hline 1 & Januari & 1420 & 25 & Januari & 1250 \\
\hline 2 & Februari & 1225 & 26 & Februari & 1325 \\
\hline 3 & Maret & 1325 & 27 & Maret & 1150 \\
\hline 4 & April & 1550 & 28 & April & 1400 \\
\hline 5 & Mei & 1750 & 29 & Mei & 1485 \\
\hline 6 & Juni & 1250 & 30 & Juni & 1730 \\
\hline 7 & Juli & 1375 & 31 & Juli & 1325 \\
\hline 8 & Agustus & 1150 & 32 & Agustus & 1140 \\
\hline 9 & September & 1200 & 33 & September & 1285 \\
\hline 10 & Oktober & 1425 & 34 & Oktober & 1225 \\
\hline 11 & November & 1215 & 35 & November & 1150 \\
\hline 12 & Desember & 1325 & 36 & Desember & 1100 \\
\hline 13 & Januari & 1350 & 37 & Januari & 1325 \\
\hline 14 & Februari & 1150 & 38 & Februari & 1355 \\
\hline 15 & Maret & 1400 & 39 & Maret & 1250 \\
\hline 16 & April & 1250 & 40 & April & 1350 \\
\hline 17 & Mei & 1650 & 41 & Mei & 1350 \\
\hline 18 & Juni & 1225 & 42 & Juni & 1450 \\
\hline 19 & Juli & 1250 & 43 & Juli & 1225 \\
\hline 20 & Agustus & 1350 & 44 & Agustus & 1350 \\
\hline 21 & September & 1150 & 45 & September & 1350 \\
\hline 22 & Oktober & 1225 & 46 & Oktober & 1225 \\
\hline 23 & November & 1450 & 47 & November & 1230 \\
\hline 24 & Desember & 1250 & & & \\
\hline
\end{tabular}

Tabel 3. Waktu Standart Tiap Work Center

\begin{tabular}{clc}
\hline No & \multicolumn{1}{c}{ Work Center } & Waktu Standart (menit) \\
\hline 1 & Cleaning Process & 12,21 \\
2 & Weighing Process & 12,58 \\
3 & Grinding Process & 140,41 \\
4 & Colour Check & 11,75 \\
5 & Remix/Wax Process & 16,23 \\
6 & Quality Check & 12,14 \\
7 & Washing Process & 16,67 \\
8 & Filtering \& Packing Process & 33,60 \\
\hline
\end{tabular}

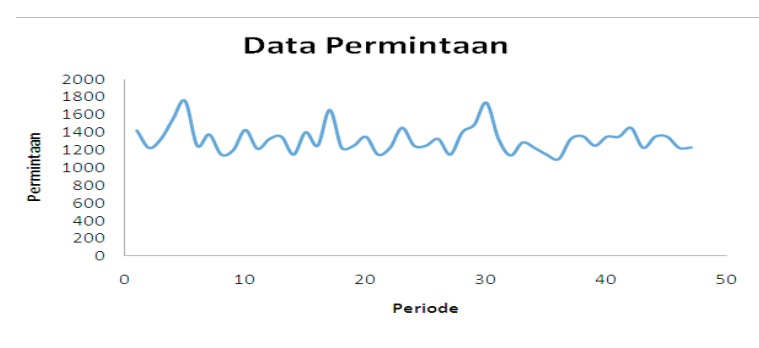

Gambar 1. Plot Data Permintaan
MSE lebih kecil dibandingkan dengan nilai pada metode yang lain. Berdasarkan hasil peramalan permintaan yang dipakai untuk periode enam bulan kedepan adalah nilai peramalan dengan metode linier regression.

Dari hasil perhitungan peramalan permintaan yang telah diketahui, maka kita 
Tabel 4. Hasil Akurasi Peramalan

\begin{tabular}{lllc}
\hline No. & \multicolumn{1}{c}{ Model Peramalan } & \multicolumn{1}{c}{ Akurasi Kesalahan } & Nilai \\
\hline 1 & Linier Regression & Bias (Mean Error) & 0 \\
& & MAD (Mean Absolute Deviation) & 108,6666 \\
\multirow{2}{*}{2} & \multirow{2}{*}{ Exponential Smoothing } & MSE (Mean Squared Error) & $19.990,21$ \\
& & Bias (Mean Error) & $-6,281$ \\
& & MAD (Mean Absolute Deviation) & 138,381 \\
3 & \multirow{2}{*}{ Weighted Moving Averages } & MSE (Mean Squared Error) & $28.962,76$ \\
& & Bias (Mean Error) & $-13,3415$ \\
& & MAD (Mean Absolute Deviation) & 127,0488 \\
4 & Moving Averages & MSE (Mean Squared Error) & $23.964,51$ \\
& & Bias (Mean Error) & $-13,9837$ \\
& & MAD (Mean Absolute Deviation) & 126,0976 \\
5 & Exponential Smoothing & MSE (Mean Squared Error) & $23.781,75$ \\
& With Trend B = 0,1 & Bias (Mean Error) & $-2,304$ \\
& & MAD (Mean Absolute Deviation) & 142,7179 \\
& & MSE (Mean Squared Error) & $31.285,72$ \\
\hline
\end{tabular}

Tabel 5. Nilai Peramalan Permintaan Tinta PMW Blue 6 Bulan

\begin{tabular}{llc}
\hline No & \multicolumn{1}{c}{ Bulan } & $\begin{array}{c}\text { Jumlah } \\
\text { Permintaan (Kg) }\end{array}$ \\
\hline 48 & Desember & 1278 \\
49 & Januari & 1277 \\
50 & Pebruari & 1275 \\
51 & Maret & 1274 \\
52 & April & 1272 \\
53 & Mei & 1270 \\
\hline
\end{tabular}

dapat menghitung kebutuhan material penyusun tinta standar jenis PMW Blue beserta waktu pemesanan bahan-baku tinta tersebut. Jumlah permintaan produk tinta standar jenis PMW Blue pada bulan berikutnya adalah sebesar $1278 \mathrm{Kg}$, maka kebutuhan dari masing-masing bahan-baku penyusun tinta standar jenis PMW Blue adalah sebagai berikut seperti pada Tabel 6 .
Setelah jumlah kebutuhan bahan baku tinta diketahui, maka selanjutnya menghitung rencana produksi tinta standar jenis PMW Blue dan rencana pemesanan masing-masing komponen dan data perusahaan telah diketahui lead time dan inventory on-hand.

Berdasarkan perencanaan kebutuhan material pada Tabel 7, maka perencanaan untuk memenuhi permintaan dan kebutuhan bahan baku yang akan dipesan hari ke-7 adalah :

1. Pigmen Blue yang harus dipesan sebesar 127,8 $\mathrm{Kg}$ atau 12,78 drum=13 drum, @ drum =10 $\mathrm{Kg}$, maka 13 × $10=130 \mathrm{Kg}$, dan sisa $2,2 \mathrm{Kg}=$ $2 \mathrm{Kg}$.

2. Resin yang harus dipesan sebesar $307,72 \mathrm{Kg}$ atau 15,34 drum=16 drum, @ drum = 20 $\mathrm{Kg}$, maka 16 × $20=320 \mathrm{Kg}$, dan sisa $13,28 \mathrm{Kg}$ $=13 \mathrm{Kg}$.

Tabel 6. Kebutuhan Bahan Baku Tinta PMW Blue

\begin{tabular}{ccccc}
\hline \multicolumn{5}{c}{ PMW Blue } \\
& \multicolumn{1}{c}{$1278 \mathrm{Kg}$} & \\
\hline Pigmen & Resin & Solven & Wax & Zat Additive \\
$(10 \%)$ & $(24 \%)$ & $(60 \%)$ & $(5 \%)$ & $(1 \%)$ \\
\hline $127,8 \mathrm{Kg}$ & $306,72 \mathrm{Kg}$ & $766,8 \mathrm{Kg}$ & $63,9 \mathrm{Kg}$ & $12,78 \mathrm{Kg}$ \\
\hline
\end{tabular}


Selanjutnya akan dilakukan perhitungan MRP untuk mengetahui kapan produksi tinta standar jenis PMW harus dilakukan dan kapan serta berapa bahan baku yang harus dipesan untuk memproduksi tinta tersebut.

1. Perencanaan produksi tinta standar PMW Blue.

Komponen : Tinta standard PMW Blue, Lot Size: $1278 \mathrm{Kg}$, Inventory On-Hand $\quad: 0$

\begin{tabular}{|c|c|c|c|c|c|c|}
\hline \multirow{2}{*}{$\begin{array}{c}\text { PMW Blue } \\
\text { Lead time = } 3 \text { hari }\end{array}$} & \multicolumn{6}{|c|}{ Hari ke } \\
\hline & 10 & 11 & 12 & 13 & 14 & 15 \\
\hline Kebutuhan kotor (kg) & & & & & & 1278 \\
\hline Persediaan di gudang $(\mathrm{kg})$ & 0 & 0 & 0 & 0 & 0 & \\
\hline Kebutuhan bersih (kg) & & & & & & 1278 \\
\hline Produksi yang direncanakan (kg) & & & 1278 & & & \\
\hline
\end{tabular}

2. Perencanaan Komponen : Pigmen Blue, Lot Size : 127,8 Kg, Inventory On-Hand : 0

\begin{tabular}{lllllllr}
\hline \multicolumn{1}{c}{ Pigmen Blue } & \multicolumn{7}{c}{ Hari ke } \\
\cline { 2 - 8 } \multicolumn{1}{c}{ Lead time $=\mathbf{5}$ hari } & $\mathbf{7}$ & $\mathbf{8}$ & $\mathbf{9}$ & $\mathbf{1 0}$ & $\mathbf{1 1}$ & $\mathbf{1 2}$ \\
\hline $\begin{array}{l}\text { Kebutuhan kotor }(\mathrm{kg}) \\
\text { Persediaan di gudang }(\mathrm{kg})\end{array}$ & 0 & 0 & 0 & 0 & 0 & 127,8 \\
Kebutuhan bersih $(\mathrm{kg})$ & & & & & & 127,8 \\
Pesanan yang direncanakan $(\mathrm{kg})$ & 127,8 & & & & & \\
\hline
\end{tabular}

3. Komponen : Resin, Lot Size : 306,72 Kg, Inventory On-Hand : 0

\begin{tabular}{lllllllc}
\hline \multicolumn{1}{c}{ Resin } & \multicolumn{7}{c}{ Hari ke } \\
\cline { 2 - 8 } \multicolumn{1}{c}{ Lead time $=\mathbf{5}$ hari } & $\mathbf{7}$ & $\mathbf{8}$ & $\mathbf{9}$ & $\mathbf{1 0}$ & $\mathbf{1 1}$ & $\mathbf{1 2}$ \\
\hline $\begin{array}{l}\text { Kebutuhan kotor }(\mathrm{kg}) \\
\text { Persediaan di gudang }(\mathrm{kg})\end{array}$ & 0 & 0 & 0 & 0 & 0 & 306,72 \\
$\begin{array}{l}\text { Kebutuhan bersih }(\mathrm{kg}) \\
\text { Pesanan yang direncanakan }(\mathrm{kg})\end{array}$ & 306,72 & & & & & 306,72 \\
\hline
\end{tabular}

4. Komponen : Solven, Lot Size: 766,8 Kg, Inventory On-Hand

\begin{tabular}{llrlcrrr}
\hline \multicolumn{1}{c}{ Solven } & \multicolumn{7}{c}{ Hari ke } \\
\cline { 2 - 7 } \multicolumn{1}{c}{ Lead time $=\mathbf{5}$ hari } & $\mathbf{7}$ & $\mathbf{8}$ & $\mathbf{9}$ & $\mathbf{1 0}$ & $\mathbf{1 1}$ & $\mathbf{1 2}$ \\
\hline Kebutuhan kotor $(\mathrm{kg})$ & & & & & & 766,8 \\
Persediaan di gudang $(\mathrm{kg})$ & 200 & 200 & 200 & 200 & 200 & \\
$\begin{array}{l}\text { Kebutuhan bersih }(\mathrm{kg}) \\
\text { Pesanan yang direncanakan }(\mathrm{kg})\end{array}$ & 566,8 & & & & & 566,8 \\
\hline
\end{tabular}

5. Komponen: Wax, Lot Size : 63,9 Kg, Inventory On-Hand $\quad: 15 \mathrm{Kg}$

\begin{tabular}{|c|c|c|c|c|c|c|}
\hline \multirow{2}{*}{$\begin{array}{c}\text { Wax } \\
\text { Lead time }=5 \text { hari }\end{array}$} & \multicolumn{6}{|c|}{ Hari ke } \\
\hline & 7 & 8 & $\mathbf{9}$ & 10 & 11 & 12 \\
\hline Kebutuhan kotor (kg) & & & & & & 63,9 \\
\hline Persediaan di gudang $(\mathrm{kg})$ & 15 & 15 & 15 & 15 & 15 & \\
\hline Kebutuhan bersih (kg) & & & & & & 48,9 \\
\hline Pesanan yang direncanakan $(\mathrm{kg})$ & 48,9 & & & & & \\
\hline \multicolumn{7}{|l|}{ Komponen : Zat Aditif, Lot Size } \\
\hline \multirow{2}{*}{$\begin{array}{c}\text { Zat Aditif } \\
\text { Lead time }=\mathbf{5} \text { hari }\end{array}$} & \multicolumn{6}{|c|}{ Hari ke } \\
\hline & 7 & 8 & 9 & 10 & 11 & 12 \\
\hline Kebutuhan kotor (kg) & & & & & & 12,78 \\
\hline Persediaan di gudang $(\mathrm{kg})$ & 15 & 15 & 15 & 15 & 15 & \\
\hline Kebutuhan bersih $(\mathrm{kg})$ & & & & & & 12,78 \\
\hline Pesanan yang direncanakan $(\mathrm{kg})$ & 12,78 & & & & & \\
\hline
\end{tabular}


Tabel 7. MRP Bulan Desember

\begin{tabular}{lccccccccc}
\hline \multirow{2}{*}{ Nama Bahan } & \multicolumn{10}{c}{ Hari ke } \\
\cline { 2 - 9 } & 6 & 7 & 8 & 9 & 10 & 11 & 12 & 13 & 14 \\
\hline PMW Blue & & & & & & & 1278 & & 1278 \\
Pigmen Blue & & 127,8 & $\mathbf{0}$ & $\mathbf{0}$ & $\mathbf{0}$ & $\mathbf{0}$ & $\mathbf{1 2 7 , 8}$ & & \\
Resin & 306,12 & $\mathbf{0}$ & $\mathbf{0}$ & $\mathbf{0}$ & $\mathbf{0}$ & $\mathbf{3 0 6 , 7 2}$ & & \\
Solven & & 566,8 & $\mathbf{2 0 0}$ & $\mathbf{2 0 0}$ & $\mathbf{2 0 0}$ & $\mathbf{2 0 0}$ & $\mathbf{7 6 6 , 8}$ & & \\
Wax & & 48,9 & $\mathbf{1 5}$ & $\mathbf{1 5}$ & $\mathbf{1 5}$ & $\mathbf{1 5}$ & $\mathbf{6 3 , 9}$ & & \\
Zat Additive & & 12,78 & $\mathbf{1 5}$ & $\mathbf{1 5}$ & $\mathbf{1 5}$ & $\mathbf{1 5}$ & $\mathbf{1 2 , 7 8}$ & & \\
Jumlah bahan baku & & 1063 & & & & & & & \\
yang dipesan & & & & & & & & & \\
Jumlah tinta yang & & & & & & 1278 & & \\
diproduksi & & & & & & & &
\end{tabular}

Tabel 8. Persedian di Gudang Bulan Januari

\begin{tabular}{lllllllll}
\hline No. & $\begin{array}{c}\text { Pesan Bahan Baku } \\
\text { (kg) }\end{array}$ & $\begin{array}{c}\text { @ } \\
\text { drum }\end{array}$ & $\begin{array}{c}\text { Kebutuhan } \\
\text { Drum) }\end{array}$ & $\begin{array}{c}\text { Pembulatan } \\
\text { (Drum) }\end{array}$ & $\begin{array}{c}\text { Jumlah } \\
(\mathbf{k g})\end{array}$ & $\begin{array}{c}\text { Sisa } \\
(\mathbf{k g})\end{array}$ & $\begin{array}{c}\text { Persediaan } \\
\text { bulat (kg) }\end{array}$ \\
\hline 1 & Pigmen & 127.8 & 10 & 12,78 & 13 & 130 & 2,20 & 2 \\
2 & Resin & 306,72 & 20 & 15,34 & 16 & 320 & 13,28 & 13 \\
3 & Solven & 566,8 & 160 & 3,54 & 4 & 640 & 73,20 & 73 \\
4 & Wax & 48,9 & 20 & 2,45 & 3 & 60 & 11,10 & 11 \\
5 & Zat Additive & 12,78 & 20 & 0 & 0 & 0 & 0,00 & 0,00 \\
\hline
\end{tabular}

3. Solven perlu melakukan pemesanan sebesar $566,8 \mathrm{Kg}$ atau 3,54 drum = 4 drum, @ drum $=160 \mathrm{Kg}$, maka $4 \times 160=640 \mathrm{Kg}$, dan sisa $73,2 \mathrm{Kg}=73 \mathrm{Kg}$.

4. Wax perlu melakukan pemesanan sebesar 48,9 $\mathrm{Kg}$ atau 2,45 drum = 3 drum, @ drum = 20 $\mathrm{Kg}$, maka $3 \times 20=60 \mathrm{Kg}$, dan sisa $11,1 \mathrm{Kg}=$ $11 \mathrm{Kg}$.

5. Zat Additive tidak perlu melakukan pemesanan karena persediaan bahan baku di gudang masih mencukupi kebutuhan.

Berdasarkan perhitungan kapasitas pada Tabel 10, maka dapat diketahui kapasitas yang dibutuhkan oleh masing-masing work center selama satu bulan (periode), kapasitas produksi dari masing-masing work center, kelebihan/ kekurangan kapasitas mesin dan operator. Dari analisis dapat diketahui, bahwa masih ada work center yang kekurangan kapasitas. Work center tersebut adalah : $\mathrm{WC}-3, \mathrm{WC}-4, \mathrm{WC}-5$, WC -6 , WC -7 . Penyesuaian yang dilakukan adalah dengan cara menambahkan shift kerja sebanyak
1 jam pada WC $-3, \mathrm{WC}-5$, WC -7 , sedangkan untuk mengatasi kekurangan pada WC -4 dan WC -6 dilakukan penambahan operator sebanyak 2 orang.

\section{SIMPULAN}

Berdasarkan perhitungan dan analisis yang telah dilakukan selama penelitian maka dapat ditarik kesimpulan bahwa: waktu standar di masing-masing elemen kerja adalah Cleaning Process=12,21 Menit, Weighing Process $=12,58$ Menit, Grinding Process = 140,41 Menit, Colour Check =11,75 Menit, Remix $/$ Wax Process =16,23 Menit, Quality Check = 12,14 Menit, Washing Process $=16,67$ Menit, dan Filtering \& Packing Process $=33,60$ menit. Permintaan produk untuk periode berikutnya sebesar $1278 \mathrm{Kg}$ dengan menggunakan metode peramalan regresi linier yang mempunyai nilai kesalahan terkecil, sehingga perencanaan kebutuhan material (MRP) untuk di pesan hari ke-7 adalah pigmen blue yang harus dipesan sebesar 127,8 Kg $=13$ drum, Resin $=307,72 \mathrm{Kg}=16$ drum, Solven $=$ 
Tabel 9. Operation Time

\begin{tabular}{llccccc}
\hline Part & $\begin{array}{l}\text { Lot Size } \\
\text { (kg) }\end{array}$ & $\begin{array}{l}\text { Work } \\
\text { Center }\end{array}$ & $\begin{array}{l}\text { Set Up } \\
\text { Time /kg } \\
\text { (menit) }\end{array}$ & $\begin{array}{l}\text { Run Time/ } \\
\text { kg } \\
\text { (menit) }\end{array}$ & $\begin{array}{l}\text { Operation } \\
\text { Time/kg } \\
\text { (menit) }\end{array}$ & $\begin{array}{l}\text { Total } \\
\text { Operation Time } \\
\text { (menit) }\end{array}$ \\
\hline & & WC -1 & 0 & 12,21 & 12,21 & 15604,38 \\
& & WC -2 & 0 & 12,58 & 12,58 & 16077,24 \\
PMW & & WC -3 & 10 & 140,41 & 150,41 & 192224 \\
Blue & 1278 & WC -4 & 0 & 11,75 & 11,75 & 15016,5 \\
& & WC -5 & 10 & 16,23 & 26,23 & 33521,94 \\
& & WC -6 & 0 & 12,14 & 12,14 & 15514,92 \\
& & WC -7 & 10 & 16,67 & 26,67 & 34084,26 \\
& & WC -8 & 10 & 33,60 & 43,60 & 55720,8 \\
\hline
\end{tabular}

Tabel 10. Kapasitas Produksi Desember

\begin{tabular}{lcccccccc}
\hline & WC-1 & WC-2 & WC-3 & WC-4 & WC-5 & WC-6 & WC-7 & WC-8 \\
\hline $\begin{array}{l}\text { Jml mesin \& } \\
\begin{array}{l}\text { Operator } \\
\text { Waktu yang }\end{array}\end{array}$ & 4 & 4 & 4 & 1 & 4 & 1 & 4 & 8 \\
$\quad$ & 10560 & 10560 & 10560 & 10560 & 10560 & 10560 & 10560 & 10560 \\
$\begin{array}{l}\text { Tersedia (menit) } \\
\text { Tingkat Utilisasi }\end{array}$ & 0,7 & 0,7 & 0,7 & 0,7 & 0,7 & 0,7 & 0,7 & 0,7 \\
$\begin{array}{l}\text { Kapasitas } \\
\text { Tersedia(menit) }\end{array}$ & 29568 & 29568 & 29568 & 14784 & 29568 & 14784 & 29568 & 59136 \\
$\begin{array}{l}\text { Kebutuhan } \\
\text { Aktual (menit) }\end{array}$ & 156044,4 & 16077,24 & 192224 & 15016,5 & 33521,94 & 15514,92 & 34084,26 & 55720,8 \\
$\begin{array}{l}\text { Kelebihan/ } \\
\text { Kekurangan } \\
\text { kapasitas (menit) }\end{array}$ & 13963,62 & 13490,76 & -162656 & $-232,5$ & $-3953,94$ & $-730,92$ & $-4516,26$ & 3415,2 \\
\hline
\end{tabular}

$566,8 \mathrm{Kg}=4$ drum, Wax $=48,9 \mathrm{Kg}=3$ drum, Zat Aditif tidak perlu melakukan pemesanan karena persediaan bahan baku digudang masih mencukupi kebutuhan. Kapasitas produksi tidak mampu memenuhi permintaan pada saat tinggi, maka perlu dilakukan lembur 1 jam dan penambahan operator 2 orang.

\section{DAFTAR PUSTAKA}

Gaspersz, V., 2005. Production Planning and Inventory Control Berdasarkan Pendekatan Sistem Terintegrasi MRP II dan JIT Menuju Manufacturing 21, Cetakan Kelima, Jakarta: PT Gramedia Pustaka Utama.
Handoko, T.H., 2003. Dasar-Dasar Manajemen Produksi dan Operasi, Edisi Pertama, Yogyakarta: BPFE.

Nasution, A. H., 1999, Perencanaan dan Pengendalian Produksi, Cetakan Pertama, Jakarta: Guna Widya.

Smith, S. B., 1989. Computer Based Production and Inventory Control , Englewood Cliffs, New Jersey: Prentice-Hall.

Sutalaksana, I.Z., Anggawisastra, R., dan Tjakraatmadja, J.H., 2006. Teknik Tata Cara Kerja, Bandung: Penerbit Jurusan Teknik Industri, Institut Teknologi Bandung.

Wignjosoebroto, S., 2008. Ergonomi, Studi Gerak dan Waktu, Edisi Pertama, Cetakan Keempat, Jakarta: Guna Widya. 